\title{
Assessment of SMADI and SWDI agricultural drought indices using remotely sensed root zone soil moisture
}

\author{
Miriam Pablos, Ángel González-Zamora, Nilda Sánchez, and José Martínez-Fernández \\ Instituto Hispanoluso de Investigaciones Agrarias (CIALE), University of Salamanca (USAL), \\ Villamayor, 37185, Spain \\ Correspondence: Miriam Pablos (mpablos@usal.es)
}

Received: 19 April 2018 - Revised: 29 June 2018 - Accepted: 18 July 2018 - Published: 18 December 2018

\begin{abstract}
The increasing frequency of drought events has expanded the research interest in drought monitoring. In this regard, remote sensing is a useful tool to globally mapping the agricultural drought. While this type of drought is directly linked to the availability of root zone soil moisture (RZSM) for plants growth, current satellite soil moisture observations only characterize the water content of the surface soil layer $(0-5 \mathrm{~cm})$. In this study, two soil moisture-based agricultural drought indices were obtained at a weekly rate from June 2010 to December 2016, using RZSM estimations at $1 \mathrm{~km}$ from the Soil Moisture and Ocean Salinity (SMOS) satellite, instead of surface soil moisture (SSM). The RZSM was estimated by applying the Soil Water Index (SWI) model to the SMOS SSM. The Soil Moisture Agricultural Drought Index (SMADI) and the Soil Water Deficit Index (SWDI) were assessed over the Castilla y León region (Spain) at $1 \mathrm{~km}$ spatial resolution. They were compared with the Atmospheric Water Deficit (AWD) and the Crop Moisture Index (CMI), both computed at different weather stations distributed over the study area. The level of agreement was analyzed through statistical correlation. Results showed that the use of RZSM does not influence the characterization of drought, both for SMADI and SWDI.
\end{abstract}

\section{Introduction}

In the last years, drought has been one of the natural disasters with the worst impact in the agricultural regions worldwide (FAO, 2018). Traditional drought indices, such as the Palmer Drought Severity Index, PDSI (Palmer, 1965), the Standardized Precipitation Index, SPI (McKee et al., 1993) or the Atmospheric Water Deficit, AWD (Purcell et al., 2003), utilize meteorological variables as drought indicators. However, the agricultural drought begins when the available soil moisture drops below a critical threshold, which can cause crop stress and adversely affect yields (Panu and Sharma, 2002; Mishra and Singh, 2010). Then, the soil moisture can be considered as the key variable of this type of drought.

The most used agricultural drought index is the Crop Moisture Index, CMI (Palmer, 1968). It is usually computed alongside the PDSI from evapotranspiration $\left(\mathrm{ET}_{0}\right)$ deficit and moisture excess, using climate-based data. Furthermore, several soil moisture-based agricultural drought indices are being developed, as the Soil Moisture Deficit Index, SMDI
(Narasimhan and Srinivasan, 2005), the Soil Water Deficit Index, SWDI (Martínez-Fernández et al., 2015) and the Soil Moisture Agricultural Drought Index, SMADI (Sánchez et al., 2016), among others.

Nowadays, there are two missions specifically dedicated to global measuring soil moisture. The first is the Soil Moisture and Ocean Salinity (SMOS), launched in 2009 by the European Space Agency, ESA (Kerr et al., 2016). SMOS L2 surface soil moisture at $15 \mathrm{~km}$ is operationally distributed by ESA. In addition, a downscaled SMOS L4 surface soil moisture at $1 \mathrm{~km}$ is provided by the Barcelona Expert Centre (BEC). The second satellite is the Soil Moisture Active Passive (SMAP) of the National Aeronautics and Space Administration (NASA), in orbit since 2015 (Chan et al, 2016). SMAP L2 surface soil moisture maps at 36 and $9 \mathrm{~km}$ are disseminated by NASA. These remotely sensed soil moisture observations are only capable of measuring the surface soil moisture (SSM) of the top soil layer (approx. $0-5 \mathrm{~cm}$ ). Meanwhile, the roots of common crops are enclosed at deeper soil 
layers, around 0-1 $\mathrm{m}$ depth (Allen et al., 1998), where the root zone soil moisture (RZSM) is defined.

The RZSM can be estimated using hydrological or land surface models. Commonly, these models are complex, requiring a high computational processing cost and many input variables as well as data assimilation techniques (MuñozSabater et al., 2007; Das et al., 2010; Dumedah et al., 2015). There are two operational RZSM products based on SMOS and SMAP, the SMOS L4 RZSM at $25 \mathrm{~km}$ provided by the Centre d'Etudes Spatiales de la Biosphere, CESBIO (Al Bitar et al., 2013) and the SMAP L4 RZSM at $9 \mathrm{~km}$, provided by the National Snow and Ice Data Center Distributed Active Archive Center, NSIDC DAAC (Reichle et al., 2017). An alternative to these hydrological models is the Soil Water Index, SWI (Wagner et al., 1999; Albergel et al., 2008). The SWI model is an exponential filter that is easy to apply for estimating the RZSM.

Since the soil profile behaves as a filter between incoming water and processes that remove it from the hydrological system (Entekhabi et al., 1996), the SSM can be highly affected by anomalous temperature or precipitation events of a particular day. Under these circumstances, the SSM may reflect inaccurate soil water conditions, whereas the RZSM actually indicates the available water storage for plants growth. Therefore, the RZSM is expected to be more appropriate than the SSM for the agricultural drought monitoring. Nonetheless, a limited number of drought indices have been calculated using in situ RZSM (Hunt et al., 2009; MartínezFernández et al., 2015), but few drought studies were found using the RZSM estimated from satellite SSM observations (Tobin et al., 2017).

This work aimed to assess the impact of the remotely sensed RZSM in two soil moisture-based agricultural drought indices, the SMADI and the SWDI, instead of using SSM. Both SMADI and SWDI indices were weekly estimated from June 2010 to December 2016 over the agricultural areas of the Castilla y León region, Spain. To assess the behavior of the indices, they were compared through statistical correlation with AWD and CMI, both obtained from meteorological data acquired at different weather stations distributed over the study area.

\section{Study area}

This research was developed in the Castilla y León region, located at the northwest of Spain $\left(39.85-43.35^{\circ} \mathrm{N}\right.$; $7.35-1.65^{\circ} \mathrm{W}$ ), as study area. This region is mainly characterized by a large plain surrounded by mountains to the North, South and East. The extension of the plain is approximately $65000 \mathrm{~km}^{2}$ and has a mean altitude of $800 \mathrm{~m}$. Its climate is continental semi-arid Mediterranean with a mean annual temperature of $11.8^{\circ} \mathrm{C}$. The Castilla y León region suffers of scarcity of water, with an average annual precipitation of $450 \mathrm{~mm}$ (González-Zamora et al., 2015). Despite this, it is

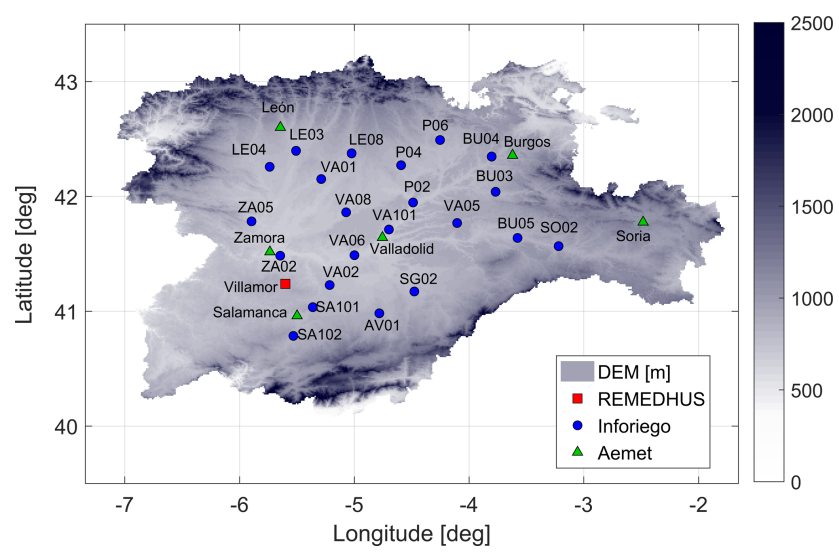

Figure 1. Digital elevation model (DEM) map of the Castilla y León region showing the location of the REMEDHUS, Inforiego and AEMet stations.

one of the largest agricultural areas of the European Union, chiefly dedicated to rainfed agriculture. In this region, croplands are usually located in areas with an elevation lower than $1100 \mathrm{~m}$, while areas at higher altitudes are mainly covered by forest-pasture. The main crop types are cereals $(73.5 \%)$, industrial crops $(13 \%)$, forages $(8 \%)$, and legumes, tubers and vegetables (5.5\%) (Pablos et al., 2017).

\section{Data}

\subsection{In situ data}

Three climatic networks were used in this study (Fig. 1). The first is the Soil Moisture Measurement Stations Network of the University of Salamanca, REMEDHUS (GonzálezZamora et al., 2015). Several weather stations are also installed in REMEDHUS, from which the Villamor station was selected. The second is Inforiego, an agro-meteorological network from the Agriculture Technological Institute of Castilla y León (ITACyL) that is dedicated to irrigation assessment. The third one is the Spanish Meteorological Agency (AEMet) network, which provided long-term weather data.

Daily data (precipitation, air temperature, relative humidity, solar radiation and wind speed) measured by the 22 agrometeorological stations of the Inforiego network and the Villamor station, were used from June 2010 to December 2016. Similarly, historical records from 1985 to 2016 of daily air temperature and precipitation acquired by six stations of the AEMet network were utilized.

As other ancillary data, the digital elevation model (DEM) provided by the ITACYL at $25 \mathrm{~m}$ of spatial resolution was used for discriminating the agricultural areas of the study region.

The surface soil database of the Duero basin from the ITA$\mathrm{CyL}$ was also employed. It contains approximately ten thou- 
sand samples with information of soil texture and organic matter (OM) contents.

\subsection{SMOS-BEC L4 SSM}

The cloud free SMOS-BEC L4 SSM v.3 product at $1 \mathrm{~km}$ over the Iberian Peninsula was used from June 2010 to December 2016. These SSM maps are obtained from the combination of daily SMOS brightness temperature and SSM (L1C and L2, both v.620), 16-day Terra Moderate Resolution Imaging Spectroradiometer (MODIS) Normalized Difference Vegetation Index, NDVI (MOD13A2 v.5) and European Centre for Medium-Range Weather Forecasts (ECMWF) land surface temperature (LST) in a downscaling algorithm (Portal et al., 2017). The downscaling is separately applied for ascending and descending SMOS orbits (06:00 and 18:00 local time, respectively).

\subsection{SMOS-CESBIO L4 RZSM}

The global SMOS-CESBIO L4 RZSM v.300 at a $25 \mathrm{~km}$ Equal Area Scalable Earth (EASE)-2 grid was employed. The RZSM maps are obtained through a double soil layer (0-40 and 40-100 cm) hydrological model (Al Bitar et al., 2013). This model is daily applied for ascending and descending orbits, but it is driven by a 3 day average of the SMOS-CESBIO L3 SSM and ancillary datasets, such as the MODIS NDVI and climatic data.

\subsection{SMAP L4 SSM and RZSM}

The global SMAP L4 SSM and RZSM v.3 geophysical data maps at a $9 \mathrm{~km}$ EASE-2 grid were used from 31 March 2015 to December 2016. Both variables (SSM and RZSM) have a temporal resolution of $3 \mathrm{~h}$ and are included in the same product. The SSM and RZSM are obtained by means of the NASA Catchment land surface model. This model is driven by the daily SMAP brightness temperature, previously interpolated to $9 \mathrm{~km}$, together with observation-based surface meteorological data forcing, including precipitation (Reichle et al, 2017).

\subsection{MODIS reflectance and LST}

The day time Aqua MODIS LST at $1 \mathrm{~km}$ (MYD11A1 v.6) and surface reflectance (SR) at $500 \mathrm{~m}$ (MYD09GA v.6) in red $(\sim 660 \mathrm{~nm})$ and near infrared bands $(\sim 860 \mathrm{~nm})$, provided by the U.S. Land Processes Distributed Active Archive Center (LP DAAC, https://lpdaac.usgs.gov, last access: 7 August 2018), were used from June 2010 to December 2016. The SR data were employed to calculate the NDVI. Both LST and SR are projected to a tile-based sinusoidal grid. The four tiles covering the study area (h17v04, h17v05, h18v04 and h18v05) were selected.

\section{Methods}

\subsection{Data pre-processing}

The agricultural drought indices were only computed at the agricultural areas of the Castilla y León region. These areas were delimited by an elevation criterion and soils with OM content higher than $4 \%$ were also discarded, because usually these conditions are out of the agricultural domain under Mediterranean conditions. To do so, the DEM was interpolated from the $25 \mathrm{~m}$ grid to a regular $1 \mathrm{~km}$ grid to match the final resolution that was used in this work (Fig. 1). Then, all input data were clipped with a mask, keeping data in areas with altitudes lower than $1100 \mathrm{~m}$ and discarding the rest.

Regarding the soil database from the ITACyL, surface samples over forested areas, defined as those with OM contents higher than $4 \%$, were discarded. The remaining samples were interpolated to the same $1 \mathrm{~km}$ grid used for the indices to obtain four maps (sand, clay, silt and OM).

The SMOS-BEC L4 SSM maps were firstly resampled to the regular $1 \mathrm{~km}$ grid. For each day, the ascending and descending maps were averaged. The resulting daily maps were weekly averaged, because the weekly temporal rate fits better with the agricultural management schedule.

In MODIS data, the 4 tiles with the LST and SR maps were mosaicked and clipped to select the study area. Later, the resulting maps were resampled, at their native spatial resolutions (LST at $1 \mathrm{~km}$ and SR at $500 \mathrm{~m}$ ) from the sinusoidal grid to a regular one. The daily SR maps were masked out using the cloud and snow/ice flags, and filtered at the highest quality. The daily NDVI maps at 500 were computed from the SR, using both bands. The NDVI maps at $500 \mathrm{~m}$ were then aggregated to the same grid of the LST. Finally, the daily LST and NDVI maps at $1 \mathrm{~km}$ were also weekly averaged.

\subsection{Estimation of root zone soil moisture}

In order to estimate a remotely sensed RZSM, the SWI model (Wagner et al., 1999) was used. The SWI was applied for each day $i$ following a recursive formulation (Albergel et al., 2008):

$\mathrm{SWI}_{i}=\mathrm{SWI}_{i-1}+K_{i}\left(\mathrm{SSM}_{i}-\mathrm{SWI}_{i-1}\right)$,

where $\mathrm{SSM}_{i}$ is the SMOS-BEC L4 SSM at $1 \mathrm{~km}$ for the day $i, \mathrm{SWI}_{i-1}$ is the SWI (i.e. the RZSM estimation) of the previous day $i-1$, and $K_{i}$ corresponds to the gain of the day $i$, which is derived by (Albergel et al., 2008):

$$
K_{i}=\frac{K_{i-1}}{K_{i-1}+e^{-\left(\frac{t_{i}-t_{i-1}}{T}\right)},}
$$

where $K_{i-1}$ denotes the gain of previous day $i-1, t_{i}$ and $t_{i-1}$ are the times of current day $i$ and previous day $i-1$, respectively, and the $T$ parameter stands for a given characteristic time length. The SWI was initialized using $\mathrm{SWI}_{1}=\mathrm{SSM}_{1}$ and $K_{1}=1$. 
The $T$ parameter represents the rate of water transfer of each soil type (Ceballos et al., 2005; Albergel et al., 2008; González-Zamora et al., 2016). The optimal $T$ values were obtained by comparing the SMAP L4 SSM and RZSM. Firstly, the $3 \mathrm{~h}$ SSM and RZSM maps were daily averaged. For each pixel, the daily SMAP SSM time series was introduced in the SWI expression with different $T$ values varying from 1 to 100 days, obtaining 100 different possible SWI time series. Then, all the 100 SWI time series were compared to the daily SMAP RZSM time series. The optimal $T$ was that obtaining the highest correlation during this comparison (Ford et al., 2014; González-Zamora et al., 2016). The resulting $T$ map at $9 \mathrm{~km}$ EASE-2 grid was interpolated to a regular $1 \mathrm{~km}$ grid. Hence, this optimal $T$ together with the daily SMOS-BEC L4 SSM, both at $1 \mathrm{~km}$, were used as inputs of the SWI. Finally, the derived daily SMOS SWI maps were also weekly averaged.

\subsection{Estimation of drought indices}

\subsubsection{Atmospheric Water Deficit (AWD)}

The AWD was previously estimated as the difference of evapotranspiration minus precipitation (Purcell et al, 2003). In this study, the weekly AWD was reversely calculated by applying a 7-day running sum separately to both input variables, as in Torres et al. (2013):

$\mathrm{AWD}_{n}=P_{n}-\mathrm{ET}_{0_{n}}$

where $P_{n}$ is the accumulated precipitation and $\mathrm{ET}_{0_{n}}$ stands for the accumulated evapotranspiration of each week $n$.

The daily precipitation was measured at the 22 Inforiego stations and at Villamor. The daily evapotranspiration was estimated by the Penman-Monteith method of the Food and Agriculture Organization of the United Nations, FAO (Allen et al., 1998).

\subsubsection{Crop Moisture Index (CMI)}

The self-calibrating PDSI tool (Wells, 2003) was employed to compute the weekly CMI (Palmer et al., 1968). The required inputs were: (i) the monthly (weekly) averaged air temperature, (ii) the monthly (weekly) accumulated precipitation, (iii) the monthly (weekly) averaged air temperature along the study period and (iv) the total available water (TAW) content. In this research, the CMI was calculated using the daily air temperature and precipitation measured in the six AEMet stations of the Castilla y León region from 1985 to 2016.

The TAW at the root zone was computed as (Allen et al., 1998):

$\mathrm{TAW}=1000 Z_{\mathrm{r}}(\mathrm{FC}-\mathrm{WP})$,

where $Z_{\mathrm{r}}$ denotes the root depth, and FC and WP are the soil water contents at field capacity and wilting point, respectively.
A root depth of $1 \mathrm{~m}$ was considered, as in Pablos et al. (2017). The FC and WP were derived by applying the pedotransfer functions (PTFs) from Rawls et al. (1982) to the surface soil data from the sand, clay and OM content of the pixels at $1 \mathrm{~km}$ overlapping the AEMet stations.

\subsubsection{Soil Moisture Agricultural Drought Index (SMADI)}

The Soil Moisture Condition Index (SMCI), the Modified Temperature Condition Index (MTCI) and the Vegetation Condition Index (VCI) were needed for the SMADI calculation. Both MTCI and VCI were weekly computed as in Sánchez et al. (2016, 2017, 2018):

$$
\begin{aligned}
\mathrm{SMCI}_{n} & =\frac{\mathrm{SM}_{\text {max }}-\mathrm{SM}_{n}}{\mathrm{SM}_{\text {max }}-\mathrm{SM}_{\text {min }}}, \\
\mathrm{MTCI}_{n} & =\frac{\mathrm{LST}_{n}-\mathrm{LST}_{\text {min }}}{\mathrm{LST}_{\text {max }}-\mathrm{LST}_{\text {min }}}, \\
\mathrm{VCI}_{n} & =\frac{\mathrm{NDVI}_{n}-\mathrm{NDVI}_{\text {min }}}{\mathrm{NDVI}_{\text {max }}-\mathrm{NDVI}_{\text {min }}},
\end{aligned}
$$

where $\mathrm{SM}_{n}$ is the soil moisture, $\mathrm{LST}_{n}$ is the MODIS LST and $\mathrm{NDVI}_{n}$ stands for the MODIS NDVI, all the three variables at $1 \mathrm{~km}$ for the current week $n$. The subscripts max and min correspond to the maximum and minimum weekly values of LST or NDVI for the study period, respectively.

The weekly SMADI was calculated using the aforementioned condition indices (Sánchez et al, 2016, 2017, 2018):

$\mathrm{SMADI}_{n}=\mathrm{SMCI}_{n} \frac{\mathrm{MTCI}_{n}}{\mathrm{VCI}_{n+2}}$,

where $\mathrm{SMCI}_{n}$ and $\mathrm{MTCI}_{n}$ are the SMCI and MTCI of the present week $n$, respectively, and $\mathrm{VCI}_{n+2}$ corresponds to the VCI of 2 weeks after. This period of 2 weeks was selected for the time adjustment of the VCI, because it provided the best correlation values when comparing with the other drought indices (Sánchez et al., 2016).

Two versions of the weekly SMCI were computed in this study depending on the soil moisture term (either the SMOSBEC L4 SSM or the SMOS-derived SWI). Accordingly, two versions of SMADI were weekly computed (SMADI SSM $_{\text {Snd }}$ SMADI $_{\text {SWI }}$, respectively).

\subsubsection{Soil Water Deficit Index (SWDI)}

The weekly SWDI was computed following MartínezFernández et al. (2015, 2016):

$\mathrm{SWDI}_{n}=10\left(\frac{\mathrm{SM}_{n}-\mathrm{FC}}{\mathrm{AWC}}\right)$,

where the $\mathrm{SM}_{n}$ is the soil moisture of the present week $n, \mathrm{FC}$ is the water content at field capacity and AWC corresponds to the available water content for plants growth, which was calculated as the difference between FC and WP. 
As for SMADI, two different versions of SWDI were calculated $\left(\mathrm{SWDI}_{\mathrm{SSM}}\right.$ and $\left.\mathrm{SWDI}_{\mathrm{SWI}}\right)$. The first version used the SMOS-BEC L4 SSM and surface soil water parameters. The FC and WP at the surface were computed as equal as in the CMI. The second version employed the SMOSderived SWI and root zone soil water parameters. The FC and WP at the root zone were estimated through the percentiles method (Martínez-Fernández et al., 2015), which was applied to the current SMOS-CESBIO L4 RZSM product at $25 \mathrm{~km}$. For that, the ascending and descending SMOSCESBIO L4 RZSM were daily averaged. The 95th and 5th percentiles maps were computed. Then, they were interpolated from $25 \mathrm{~km}$ to the regular $1 \mathrm{~km}$ grid.

\subsection{Comparison strategy}

The two versions of SMADI and SWDI were processed and four datasets of weekly maps (SMADI $_{S S M}, S_{\text {SMAI }}$ SWI,

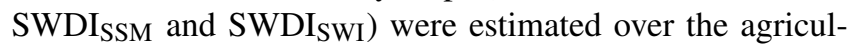
tural areas of the Castilla y León region. The four time series of the pixels at $1 \mathrm{~km}$ covering the in situ stations were extracted. They were compared with the AWD time series at the Inforiego and Villamor stations, and the CMI time series at the AEMet stations. Since there is not a precise and universal definition of the drought concept, the AWD and CMI cannot be assumed as absolute "ground-truth", but a benchmark of drought conditions computed from independent groundbased data. In addition, these meteorological-based datasets have been a good proxy for the assessment of agricultural drought in previous research (Martínez-Fernández et al., 2015, 2016; Pablos et al., 2017; Paredes-Trejo and Barbosa, 2017; Sánchez et al., 2016, 2017, 2018). The level of agreement between the time series was analyzed by means of the Pearson's correlation coefficient $(R)$. To assess a possible mismatch of time between drought indices, the SMADI ${ }_{S W I}$

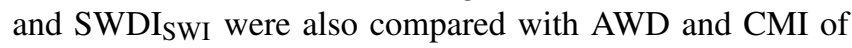
the same week and with those of 1,2 and 3 antecedent weeks.

\section{Results and discussion}

\subsection{Comparison with AWD}

The weekly evolution of the AWD, SMADI ${ }_{S W I}$ and SWDI $_{\text {SWI }}$ time series showed very similar seasonal cycles (Fig. 2), alternating dry periods during summer and wet periods during winter. Furthermore, the three agricultural drought indices adequately captured the vegetation growing season of the study area. Since SMADI defines drought with an opposite sign than AWD, CMI and SWDI (Sánchez et al, 2016, 2017, 2018), its vertical axis was plotted increasing downward and its drought threshold (SMADI $=1)$ was aligned to the zero of the other indices.

There was a certain delay between the SMADI SwI variations with respect to the AWD variations, especially at the onset of the drought events (Fig. 2a). The quicker response of AWD is consistent with the nature of this drought index, directly linked to processes that occur at the surfaceatmosphere layer. This delay was also observed in a previous study, where SMADI was estimated from the SMOS SSM (Pablos et al., 2017). In that case, the delay of SMADI was related to the time lag between the occurrence of drought and the NDVI changes (Ji and Peters, 2003; Wang et al., 2001).

A similar delay was also evident between the AWD and

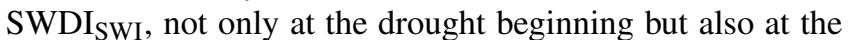
endings (Fig. 2b). This is intrinsically related to the use of the SWI, because the SSM changes are faster than the water changes of deeper soil layers. The different dynamics of the processes that occur at the atmosphere and the soil systems produced around a one-week lag of the soil moisture variations under meteorological drought conditions (Changnon, 1987). The delay of SWDI was also observed when the SWDI was computed using the in situ RZSM (MartínezFernández et al., 2015), but it was not detected when using the SMOS SSM (Martínez-Fernández et al., 2016; Pablos et al., 2017; Paredes-Trejo and Barbosa, 2017). Similar results were obtained at the other Inforiego stations of this work and Villamor (not shown).

The correlations obtained from the comparison of

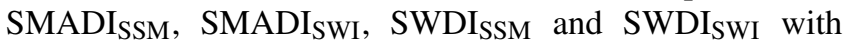
AWD (Fig. 3) showed values that were in line with the results of Fig. 2. As expected, negative correlations were obtained when comparing SMADI and AWD. In both SSMderived indices, strong correlations were obtained from the comparison with AWD of the same week $(R \approx-0.59$ for SMADI $_{\mathrm{SSM}}$ and $R \approx 0.77$ for $\mathrm{SWDI}_{\mathrm{SSM}}$, in median). These results were similar to those obtained in several previous studies (Martínez-Fernández et al., 2016; Pablos et al., 2017; Paredes-Trejo and Barbosa, 2017). By contrast, the correlations between the SWI-derived indices with AWD of the same week became slightly weaker for SMADISWI ( $R \approx-0.55$, in median, Fig. 3a) and noteworthy weaker for SWDI $_{\text {SWI }}(R \approx 0.60$, in median, Fig. $3 \mathrm{~b}$ ).

In both indices, the comparison against the AWD computed 1,2 or 3 weeks before performed slightly stronger correlations for $\operatorname{SMADI}_{\mathrm{SWI}}(R \approx-0.61,-0.63$ and -0.62 , respectively, in median) and considerably higher correlations for $\mathrm{SWDI}_{\mathrm{SWI}}(R \approx 0.72,0.71$ and 0.71 , respectively, in median) than when no time lag was taken into account. A lag of 2-3 weeks of the vegetation response to precipitation was already detected by Zhang et al. (2013).

In general, considering the 25th and 50th percentiles of the boxplots, a delay duration of two weeks obtained the best correlations for both indices. This time lag approximately agrees with the median value of the optimal $T$ over the study area (13 days). Therefore, the SSM-derived indices performed similar degree of agreement with AWD of the same week than that of the SWI-derived indices with AWD of 2 antecedent weeks. 

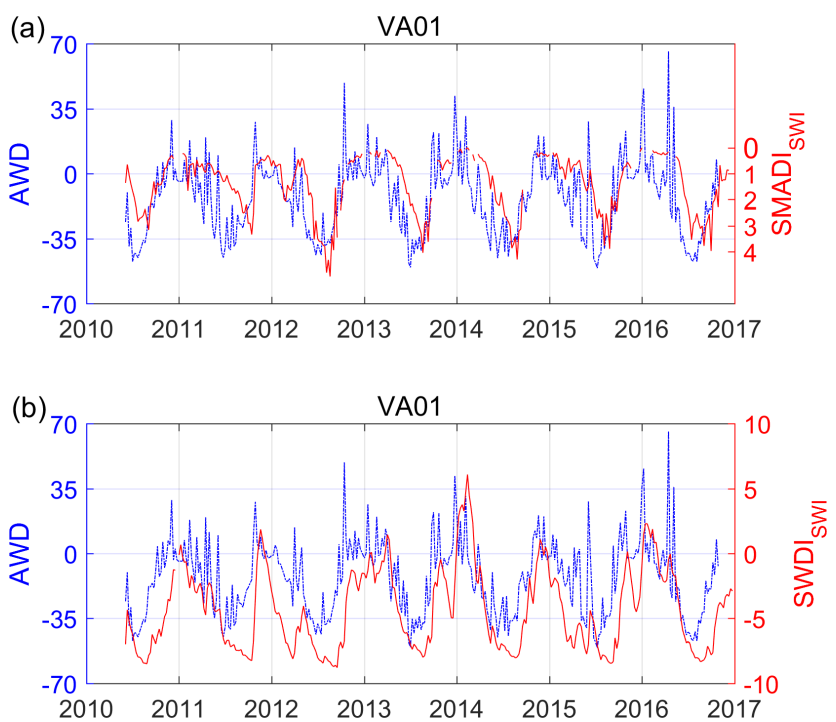

Figure 2. Time series of the weekly AWD and SMADI SWI $_{\text {(a), and }}$ SWDI $_{\text {SWI }}$ (b) at the VA01 station of Inforiego, as an example. Since $\mathrm{SMADI}=1$ and $\mathrm{AWD}=0$ are the threshold for drought (Pablos et al., 2017), both values coincide in the $y$-axis. In addition, note that the $y$-axis of SMADI is oriented downward.
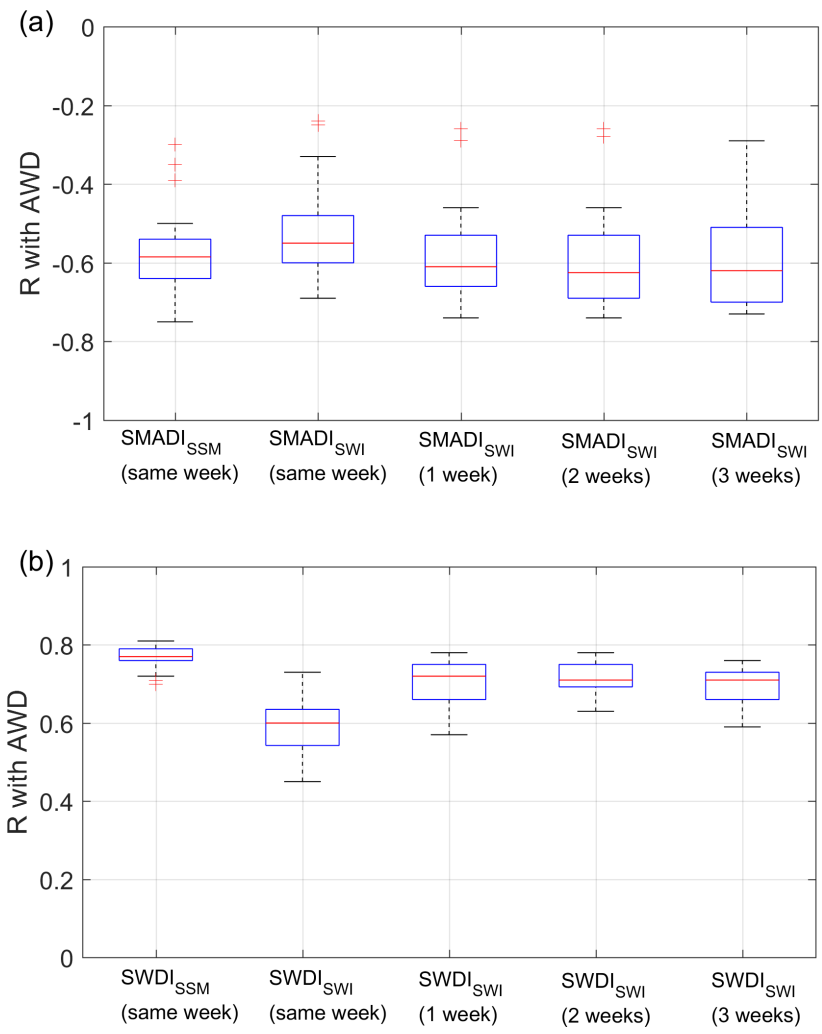

Figure 3. Correlation $(R)$ of the SMADI (a) and the SWDI (b) obtained using the SMOS SSM and SWI, with the AWD of the same week and 1, 2 or 3 antecedent weeks at the 22 Inforiego stations and Villamor. All values were significant ( $p$-value $<0.05$ ).
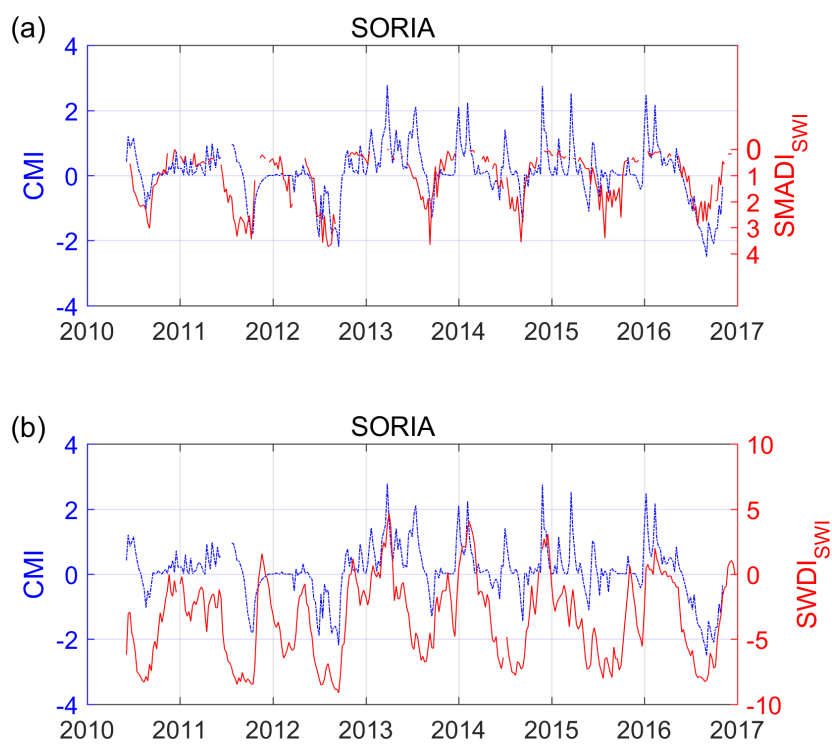

Figure 4. Time series of the weekly CMI and SMADI SWI $_{\text {(a), and }}$ SMDI $_{\text {SWI }}$ (b) at the Soria station of the AEMet, as an example. Since SMADI $=1$ and $\mathrm{CMI}=0$ are the threshold for drought (Pablos et al., 2017), both values coincide in the $y$-axis. In addition, note that the $y$-axis of SMADI is oriented downward.

\subsection{Comparison with $\mathrm{CMI}$}

The weekly CMI, SMADI ${ }_{\text {SWI }}$ and SWDI $_{\text {SWI }}$ time series at one AEMet station displayed similar seasonal periods (Fig. 4) than AWD in Fig. 2. Note that SMADI was also plotted with its vertical axis increasing downward. However, no delay was observed between the CMI and the SMADI ${ }_{\text {SWI }}$ variations, showing a good correspondence in time (Fig. 4a), as previously found (Pablos et al., 2017; Sánchez et al., 2016, 2018). This could be due to the fact that CMI takes into account the effective soil rooting depth and the soil characteristics, instead of using only climatic data like AWD.

In the case of SWDI ${ }_{S W I}$, there were not conclusive results about the existence of a delay in the comparison with CMI (Fig. 4b). As in the case of AWD, previous research showed a time lag between SWDI and CMI when using the in situ RZSM (Martínez-Fernández et al., 2015), but no delay was found when the SMOS SSM was utilized instead (MartínezFernández et al., 2016; Pablos et al., 2017). Similar results were obtained at the other AEMet stations of this work (not shown).

The correlation coefficients obtained from the comparison of SMADI ${ }_{S S M}$, SMADI $_{\text {SWI }}$, SWDI $_{\text {SWI }}$ and SWDI SWI $_{\text {with }}$ CMI (Fig. 5) displayed similar results to those discussed in Fig. 4. As in the case of AWD, negative correlation coefficients were obtained between SMADI and CMI, in agreement with their definitions. Both SMOS SSM-derived and SWI-derived SMADI had very similar correlations in the comparison with CMI of the same week (both $R \approx-0.59$, in median, Fig. 5a). These correlation values decreased in 

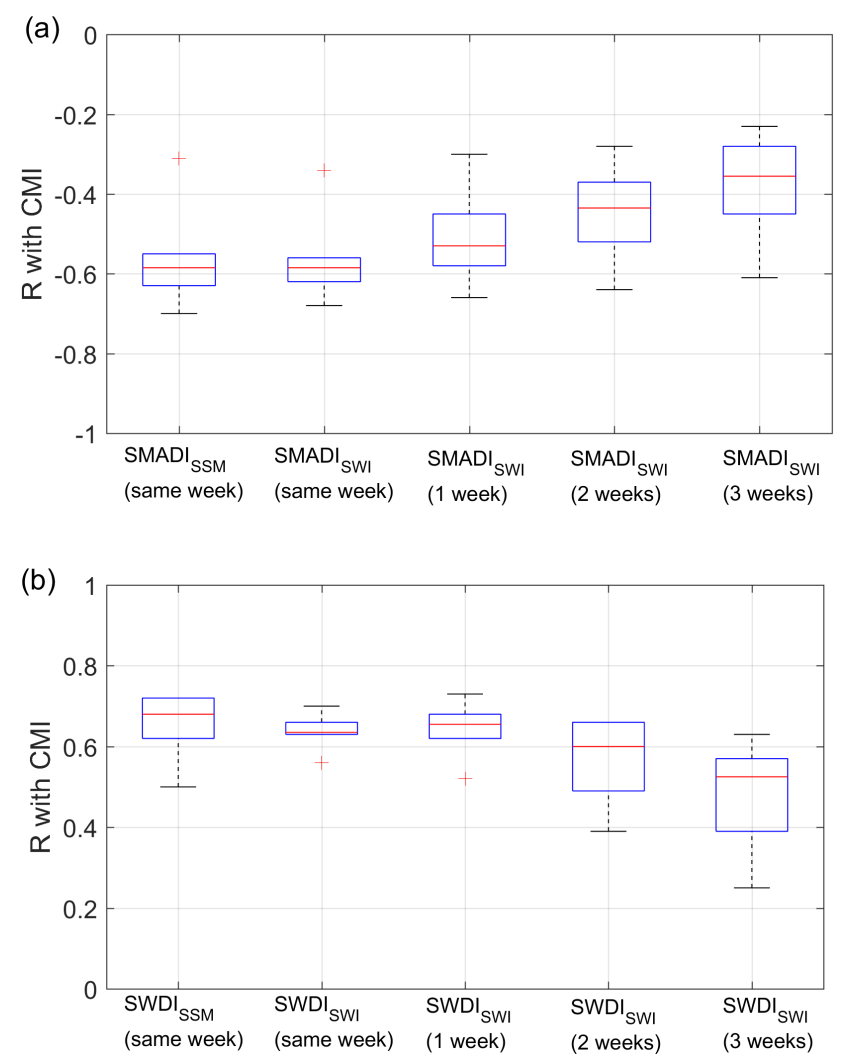

Figure 5. Correlation $(R)$ of the SMADI (a) and SWDI (b) obtained using the SMOS SSM and SWI, with the CMI of the same week and 1, 2 or 3 antecedent weeks at the six AEMet stations. Only significant values $(p$-value $<0.05)$ were considered.

the comparison with CMI of 1,2 , or 3 antecedent weeks ( $R \approx-0.54,-0.44$ and -0.36 , respectively, in median). This confirms that SMADI and CMI cycles are synchronized, as observed in Fig. 4a.

When analyzing the correlations of CMI with SWDI (Fig. 5b), the use of the SMOS SWI slightly made decrease the correlation coefficients with respect the use of SSM ( $R \approx 0.68$ for $\mathrm{SWDI}_{\mathrm{SSM}}$ and $R \approx 0.64$ for $\mathrm{SWDI}_{\mathrm{SWI}}$, in median). In addition, the correlations between SWDI SWI $_{\text {and }}$ CMI of the antecedent 1, 2 or 3 weeks displayed similar or lower values than when no delay was considered $(R \approx 0.66$, 0.60 and 0.30 , in median). This result suggests that there is not lag of time between CMI and SWDI possible duration would be around one week. Nevertheless, further research is needed to assess this issue as well as to evaluate the results with AWD and CMI in other regions with different environmental conditions. During the comparison with CMI, the level of agreement of the SWI-derived indices was similar to that of the SSM-based indices.
Table 1. Correlation $(R)$ between SMADI SSM $_{\text {and SWDI }}$ SSM, and

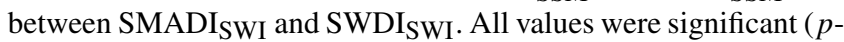
value $<0.05)$. The number of weeks with available data $(N)$ is also included.

\begin{tabular}{|c|c|c|c|}
\hline Stations & $\begin{array}{r}\text { SMADI }_{\text {SSM vs }} \\
\text { SWDI }_{S S M}\end{array}$ & $\begin{array}{r}\text { SMADI }_{\text {SWI }} \text { Vs } \\
\text { SWDI }_{\text {SWI }}\end{array}$ & $\begin{array}{r}N \\
\text { (weeks) }\end{array}$ \\
\hline AV01 & -0.74 & -0.80 & 294 \\
\hline BU03 & -0.77 & -0.79 & 286 \\
\hline BU04 & -0.75 & -0.82 & 270 \\
\hline BU05 & -0.74 & -0.80 & 288 \\
\hline LE03 & -0.69 & -0.68 & 303 \\
\hline LE04 & -0.28 & -0.22 & 303 \\
\hline LE08 & -0.70 & -0.74 & 300 \\
\hline P02 & -0.70 & -0.77 & 290 \\
\hline P04 & -0.57 & -0.65 & 298 \\
\hline P06 & -0.68 & -0.74 & 289 \\
\hline SA101 & -0.48 & -0.49 & 272 \\
\hline SA102 & -0.49 & -0.49 & 305 \\
\hline SG02 & -0.65 & -0.71 & 278 \\
\hline $\mathrm{SO} 02$ & -0.78 & -0.85 & 288 \\
\hline VA01 & -0.74 & -0.79 & 303 \\
\hline VA02 & -0.59 & -0.69 & 278 \\
\hline VA05 & -0.65 & -0.74 & 274 \\
\hline VA06 & -0.63 & -0.68 & 294 \\
\hline VA08 & -0.82 & -0.87 & 302 \\
\hline VA101 & -0.70 & -0.76 & 290 \\
\hline ZA02 & -0.70 & -0.68 & 291 \\
\hline ZA05 & -0.65 & -0.68 & 280 \\
\hline VILLAMOR & -0.72 & -0.80 & 276 \\
\hline BURGOS & -0.66 & -0.72 & 239 \\
\hline LEÓN & -0.68 & -0.71 & 303 \\
\hline SALAMANCA & -0.71 & -0.75 & 291 \\
\hline SORIA & -0.76 & -0.84 & 270 \\
\hline VALLADOLID & -0.36 & -0.41 & 287 \\
\hline ZAMORA & -0.81 & -0.84 & 287 \\
\hline
\end{tabular}

\subsection{Comparison of SMADI with SWDI}

The correlation analysis between SMADI and SWDI clearly showed a high agreement (Table 1), both with SMOS SSM $(R \approx-0.28$ to $-0.82 ;-0.70$ in median $)$ and SWI $(R \approx-0.22$ to $-0.85 ;-0.74$ in median). Additionally, the correlation differences between the SSM and SWI-derived indices were very low $(\Delta R \approx 0$ to 0.10 , in absolute value) to be significant. Thus, the results of both approaches were comparable, as previously observed in the assessment with AWD and CMI. Notwithstanding, in a detailed analysis of the correlation coefficients, 24 out of the total 29 stations obtained stronger correlations in the SWI approach. This suggests a certain trend toward a correlation improvement when the RZSM estimation was used. The high number of weeks with available data ( $N \approx 239$ to 305 weeks) of a total 342 weeks ensures that the values were robustly computed, as in the previous comparisons with AWD and CMI. However, no conclusions should be inferred from these results 
because they may hide self-adjustments or other artifacts behind this direct comparison.

\section{Conclusions}

Since the launch of recent satellite missions dedicated to soil moisture, new applications have been emerged using it as a key agricultural and hydrological variable. Among them, the number of drought approaches is increasing and the results improving. As a great leap forward, several research tries to overcome the drawback of using the soil moisture at surface level derived from remote measurements. With the same aim, two agricultural drought indices, SMADI and SWDI, were applied using remotely sensed soil moisture both at the surface layer (directly retrieved from the sensor observations) and at the root zone (estimated by applying the SWI model to the SSM). The results showed that the use of the RZSM estimation does not influence the characterization of drought through SMADI and SWDI, both in comparison with a meteorological drought index (AWD) and an agricultural one (CMI).

Both SMADI and SWDI showed a similar capability for agricultural drought monitoring, and it was highlighted that a certain time lag should be computed between the at-surface variables (SSM, precipitation) and the RZSM, due to the different response time of the associated processes. This lag is consistent with the SWI model, which takes into account the time lapse of the water transfer from the surface to the deeper soil layers.

The use of RZSM estimations from remote sensing offers a new opportunity for drought monitoring and, in a broadly sense, for many agricultural management applications.
Data availability. The data of the Villamor station are available upon request. The data of Inforiego are freely accessible (http://www.inforiego.org, ITACyL, 2018a). The data of AEMet are also accessible for free (http://www.aemet.es, AEMet, 2018). The digital elevation model (DEM) of the study area was provided by the ITACyL, as well as the surface soil database (http://suelos.itacyl.es, ITACyL, 2018b). The authors especially thank Gerard Portal and Mercè Vall-llossera from the Technical University of Catalonia (UPC) and the BEC (http://bec.icm.csic.es/land-datasets, BEC, 2018) for providing the new cloud-free SMOS-BEC L4 SSM v.3 product. The SMOS-CESBIO L4 RZSM was generated by the CESBIO and disseminated by the CATDS (http://www.catds.fr/Products/ Available-products-from-CEC-SM/L4-Land-research-products, CESBIO and CATDS, 2018). An updated version of the SMAP L4 SSM and RZSM variables are accessible at the NSIDC DAAC (https://nsidc.org/data/SPL4SMGP/versions/4, NSIDC DACC, 2018). The Aqua MODIS LST and surface reflectance were provided by the NASA Land Processes Distributed Active Archive Center (https://lpdaac.usgs.gov, LP DAAC, 2018). 


\section{Appendix A: Acronyms}

For easy reading of this research, all the acronyms were alphabetically summarized in the following list:

AEMet: Spanish Meteorological Agency

AWD: Available Water Content

AWD: Atmospheric Water Deficit

BEC: Barcelona Expert Centre

CESBIO: Centre d'Etudes Spatiales de la Biosphere

CMI: Crop Moisture Index

DEM: Digital Elevation Model

EASE: Equal Area Scalable Earth

ECMWF: European Centre for Medium-Range Weather Forecasts

ESA: European Space Agency

FC: Field Capacity

ITACyL: Agriculture Technological Institute of Castilla y León

LP DAAC: Land Processes Distributed Active Archive Center

LST: Land Surface Temperature

MODIS: Moderate Resolution Imaging Spectroradiometer

MTCI: Modified Temperature Condition Index

NASA: National Aeronautics and Space Administration

NDVI: Normalized Difference Vegetation Index

NSIDC DAAC: National Snow and Ice Data Center Distributed Active Archive Center

PDSI: Palmer Drought Severity Index

PTF: Pedotransfer Function

REMEDHUS: Soil Moisture Measurements Station Network of the University of Salamanca
RZSM: Root Zone Soil Moisture

SMADI: Soil Moisture Agricultural Drought Index

SMAP: Soil Moisture Active Passive

SMCI: Soil Moisture Condition Index

SMDI: Soil Moisture Deficit Index

SMOS: Soil Moisture and Ocean Salinity

SPI: Standardized Precipitation Index

SSM: Surface Soil Moisture

SWDI: Soil Water Deficit Index

SWI: Soil Water Index

TAW: Total Available Water

VCI: Vegetation Condition Index

WP: Wilting Point 
Author contributions. The initial idea for this research was conceived by all the four authors. The REMEDHUS, Inforiego and AEMet climatic data were prepared by ÁGZ. All the satellite data were downloaded by MP. The soil database data and the digital elevation model were prepared by NS. The SMOS SWI was computed by ÁGZ. All the other data processing was performed by MP, who also collected all the results. MP, NS and JMF equally contributed to the interpretation of the results. The first manuscript was written by MP. The four authors revised the final manuscript and approved it.

Competing interests. The authors declare that they have no conflict of interest.

Special issue statement. This article is part of the special issue "Earth Observation for Integrated Water and Basin Management: New possibilities and challenges for adaptation to a changing environment". It is a result of The Remote Sensing \& Hydrology Symposium, Cordoba, Spain, 8-10 May 2018.

Acknowledgements. The study was supported by the Junta de Castilla y Léon (JCyL) and the European Regional Development Fund (ERDF) through the project SA007U16, and Spanish Ministry of Economy and Competitiveness with the projects PROMISES: ESP2015-67549-C3-3-R and L-BAND: ESP2017-89463-C3-3-R.

Edited by: Ana Andreu

Reviewed by: two anonymous referees

\section{References}

Albergel, C., Rüdiger, C., Pellarin, T., Calvet, J.-C., Fritz, N., Froissard, F., Suquia, D., Petitpa, A., Piguet, B., and Martin, E.: From near-surface to root-zone soil moisture using an exponential filter: an assessment of the method based on in-situ observations and model simulations, Hydrol. Earth Syst. Sci., 12, 1323-1337, https://doi.org/10.5194/hess-12-1323-2008, 2008.

Al Bitar, A., Kerr, Y. H., Merlin, O., Cabot, F., and Wigneron, J. P.: Global drought index from SMOS soil moisture, IEEE Int. Geos. Remote Sens. Symp. (IGARSS), Melbourne, Australia, 2013.

Allen, R. G., Pereira, L. S., Raes, D., and Smith, M.: Crop evapotranspiration: Guidelines for computing crop water requirements, Food and Agric. Org. of the United Nations (FAO), Rome, Italy, 1998.

AEMet (Spanish Meteorological Agency): Climatic data of the AEMet network, available at: http://www.aemet.es, last access: 7 August 2018.

BEC (Barcelona Expert Centre): SMOS-BEC L4 surface soil moisture product, available at: http://bec.icm.csic.es/land-datasets, last access: 7 August 2018.

CESBIO (Centre d'Etudes Spatiales de la Biosphere) and CATDS (Centre Aval de Traitement des Donées SMOS): SMOSCESBIO L4 root zone soil moisture product, available at: http: //www.catds.fr/Products/Available-products-from-CEC-SM/ L4-Land-research-products, last access: 7 August 2018.
Changnon, S: Detecting Drought Conditions in Illinois, Illinois State Water Survey, Champaign, Circular 169, 1987.

Chan, S. K., Bindlish, R., O' Neill, P. E., Njoku, E., Jackson, T. J., Colliander, A., Chen, F., Burgin, M., Dunbar, S., Piepmeier, J., Yueh, S., Entekhabi, D., Cosh, M. H., Caldwell, T., Walker, J., Wu, X., Berg, A., Rowlandson, T., Pacheco, A., McNairn, H., Thibeault, M., Martínez-Fernández, J., GonzálezZamora, Á., Seyfried, M., Bosch, D., Starks, P., Goodrich, D., Prueger, J., Palecki, M., Small, E. E., Zreda, M., Calvet, J. C., Crow, W. T., and Kerr, Y. H.: Assessment of the SMAP passive soil moisture product, IEEE T. Geosci. Remote, 54, 4994-5007, https://doi.org/10.1109/tgrs.2016.2561938, 2016.

Ceballos, A., Scipal, K., Wagner, W., and Martínez-Fernández, J.: Validation of ERS scatterometer-derived soil moisture data in the central part of the Duero Basin, Spain, Hydrol. Process., 19, 1549-1566, https://doi.org/10.1002/hyp.5585, 2005.

Das, N. N., Mohanty, B. P., and Njoku, E. G.: Profile soil moisture across spatial scales under different hydroclimatic conditions, Soil Sci., 175, 315-319, https://doi.org/10.1097/SS.0b013e3181e83dd3, 2010.

Dumedah, G., Walker, J. P., and Merlin, O.: Root-zone soil moisture estimation from assimilation of downscaled soil moisture and ocean salinity data, Adv. Water Resour., 84, 14-22, https://doi.org/10.1016/j.advwatres.2015.07.021, 2015.

Entekhabi, D., Rodriguez-Iturbe, I., and Castelli, F.: Mutual interaction of soil moisture state and atmospheric processes, J. Hydrol., 184, 3-17, https://doi.org/10.1016/0022-1694(95)02965-6, 1996.

FAO: 2017 The impact of disasters and crises in agriculture and food security, Food and Agriculture Organization of the United Nations (FAO), Italy, 2018.

Ford, T. W., Harris, E., and Quiring, S. M.: Estimating root zone soil moisture using near-surface observations from SMOS, Hydrol. Earth Syst. Sci., 18, 139-154, https://doi.org/10.5194/hess18-139-2014, 2014.

González-Zamora, Á., Sánchez, N., Martínez-Fernández, J., Gumuzzio, A., Piles, M., and Olmedo, E.: Long-term smos soil moisture products: A comprehensive evaluation across scales and methods in the Duero basin (Spain), Phys. Chem. Earth, 83-84, 123-136, https://doi.org/10.1016/j.pce.2015.05.009, 2015.

González-Zamora, Á., Sánchez, N., Martínez-Fernández, J., and Wagner, W.: Root-zone plant available water estimation using the SMOS-derived soil water index, Adv. Water Resour., 96, 339353, https://doi.org/10.1016/j.advwatres.2016.08.001, 2016.

Hunt, E. D., Hubbard, K. G., Wilhite, D. A., Arkebauer, T. J., and Dutcher, A. L.: The development and evaluation of a soil moisture index, Int. J. Climatol., 29, 747-759, https://doi.org/10.1002/joc.1749, 2009.

ITACyL (Agriculture Technological Institute of Castilla y León): Climatic data of the Inforiego network, available at: http://ww. inforiego.org, last access: 7 August 2018a.

ITACyL (Agriculture Technological Institute of Castilla y León): Surface soil database, available at: http://suelos.itacyl.es, last access: 7 August 2018b.

Ji, L. and Peters, A. J.: Assessing vegetation response to drought in the northern great plains using vegetation and drought indices, Remote Sens. Environ., 87, 85-98, https://doi.org/10.1016/S0034-4257(03)00174-3, 2003. 
Kerr, Y. H., Al-Yaari, A., Rodríguez-Fernández, N., Parrens, M., Molero, B., Leroux, D., Bircher, S., Mahmoodi, A., Mialon, A., Richaume, P., Delwart, S., Al Bitar, A., Pellarin, T., Bindlish, R., Jackson, T. J., Rüdiger, C., Waldteufel, P., Mecklenburg, S., and Wigneron, J. P.: Overview of SMOS performance in terms of global soil moisture monitoring after six years in operation, Remote Sens. Environ., 180, 40-63, https://doi.org/10.1016/j.rse.2016.02.042, 2016.

LP DAAC (Land Processes Distributed Active Archive Center): MODIS data, https://lpdaac.usgs.gov, last access: 7 August 2018.

Martínez-Fernández, J., González-Zamora, A., Sánchez, N., and Gumuzzio, A.: A soil water based index as a suitable agricultural drought indicator, J. Hydrol., 522, 265-273, https://doi.org/10.1016/j.jhydrol.2014.12.051, 2015.

Martínez-Fernández, J., González-Zamora, Á., Sánchez, N., Gumuzzio, A., and Herrero-Jiménez, C. M.: Satellite soil moisture for agricultural drought monitoring: Assessment of the smos derived soil water deficit index, Remote Sens. Environ., 177, $277-$ 286, https://doi.org/10.1016/j.rse.2016.02.064, 2016.

McKee, T. B., Doesken, N. J., and Kleist, J.: The relationship of drought frequency and duration to time scales, Proceedings of the 8th Conference on Applied Climatology Boston, MA, 179183, 1993.

Mishra, A. K. and Singh, V. P.: A review of drought concepts, J. Hydrol., 391, 202-216, https://doi.org/10.1016/j.jhydrol.2010.07.012, 2010.

Muñoz-Sabater, J., Jarlan, L., Calvet, J. C., Bouyssel, F., and De Rosnay, P.: From near-surface to root-zone soil moisture using different assimilation techniques, J. Hydrometeorol., 8, 194-206, https://doi.org/10.1175/jhm571.1, 2007.

Narasimhan, B. and Srinivasan, R.: Development and evaluation of soil moisture deficit index (SMDI) and evapotranspiration deficit index (ETDI) for agricultural drought monitoring, Agr. Forest Meteorol., 133, 69-88, https://doi.org/10.1016/j.agrformet.2005.07.012, 2005.

NSIDC DACC (National Snow and Ice Data Center Distributed Active Archive Center),:SMAP L4 soil moisture product, available at: https://nsidc.org/data/SPL4SMGP/versions/4, last access: 7 August 2018.

Pablos, M., Martínez-Fernández, J., Sánchez, N., and GonzálezZamora, Á.: Temporal and Spatial Comparison of Agricultural Drought Indices from Moderate Resolution Satellite Soil Moisture Data over Northwest Spain, Remote Sens., 9, 1168, https://doi.org/10.3390/rs9111168, 2017.

Palmer, W. C.: Meteorological drought, in: Research paper no. 45, edited by: Connor, J. T. and White, R. M., U.S. Weather Bureau, Washington, DC, USA, 1965.

Palmer, W. C.: Keeping track of crop moisture conditions, nationwide: The new crop moisture index, Weatherwise, 21, 156-161, https://doi.org/10.1080/00431672.1968.9932814, 1968.

Panu, U. S. and Sharma, T.: Challenges in drought research: Some perspectives and future directions, Hydrol. Sci. J., 47, S19-S30, https://doi.org/10.1080/02626660209493019, 2002.

Paredes-Trejo, F. and Barbosa, H.: Evaluation of the SMOS-derived Soil Water Deficit Index as agricultural drought index in northeast of Brazil, Water, 9, 377, https://doi.org/10.3390/w9060377, 2017.
Portal, G., Vall-1lossera, M., Piles, M., Camps, A., Chaparro, D., Pablos, M., and Rossato, L.: A spatially consistent downscaling approach for SMOS using an adaptive moving window, IEEE Int. Geosc. Remote Sens. Symp. (IGARSS) 4151-4153, https://doi.org/10.1109/IGARSS.2017.8127915, Fort Worth, Texas, USA, 2017.

Purcell, L. C., Sinclair, T. R., and McNew, R. W.: Drought avoidance assessment for summer annual crops using longterm weather data research supported in part by the united soybean board, project no. 1238, Agron. J., 95, 1566-1576, https://doi.org/10.2134/agronj2003.1566, 2003.

Rawls, W. J., Brakensiek, D. L., and Saxtonn, K. E.: Estimation of soil water properties, T. ASABE, 25, 1316-1320, https://doi.org/10.13031/2013.33720, 1982.

Reichle, R. H., De Lannoy, G. J. M., Liu, Q., Ardizzone, J. V., Colliander, A., Conaty, A., Crow, W., Jackson, T. J., Jones, L. A., Kimball, J. S., Koster, R. D., Mahanama, S. P., Smith, E. B., Berg, A., Bircher, S., Bosch, D., Caldwell, T. G., Cosh, M., González-Zamora, A., Collins, C. D. H., Jensen, K. H., Livingston, S., Lopez-Baeza, E., Martínez-Fernández, J., McNairn, H., Moghaddam, M., Pacheco, A., Pellarin, T., Prueger, J., Rowlandson, T., Seyfried, M., Starks, P., Su, Z., Thibeault, M., van der Velde, R., Walker, J., Wu, X., and Zeng, Y.: Assessment of the SMAP level-4 surface and root-zone soil moisture product using in situ measurements, J. Hydrometeorol., 18, 2621-2645, https://doi.org/10.1175/jhm-d-17-0063.1, 2017.

Sánchez, N., González-Zamora, Á., Piles, M., and MartínezFernández, J.: A new soil moisture agricultural drought index (SMADI) integrating MODIS and SMOS products: A case of study over the Iberian Peninsula, Remote Sens., 8, 287, https://doi.org/10.3390/rs8040287, 2016.

Sánchez, N., González-Zamora, Á., Martínez-Fernández, J., Piles, M., Pablos, M., Wardlow, B., Tadesse, T., and Svoboda, M. D.: Preliminary assessment of an integrated smos and modis application for global agricultural drought monitoring, IEEE Int. Geosc. Remote Sens. Symp. (IGARSS), https://doi.org/10.1109/IGARSS.2017.8127374, Fort Worth, Texas, USA, 2017.

Sánchez, N., González-Zamora, Á., Martínez-Fernández, J., Piles, M., and Pablos, M.: Integrated remote sensing approach to global agricultural drought monitoring, Agr. Forest Meteorol., 259, 141-153, https://doi.org/10.1016/j.agrformet.2018.04.022, 2018.

Tobin, K. J., Torres, R., Crow, W. T., and Bennett, M. E.: Multidecadal analysis of root-zone soil moisture applying the exponential filter across CONUS, Hydrol. Earth Syst. Sci., 21, 44034417, https://doi.org/10.5194/hess-21-4403-2017, 2017.

Torres, G. M., Lollato, R. P., and Ochsner, T. E.: Comparison of drought probability assessments based on atmospheric water deficit and soil water deficit, Agron. J., 105, 428-436, https://doi.org/10.2134/agronj2012.0295, 2013.

Wang, J., Price, K. P., and Rich, P. M.: Spatial patterns of NDVI in response to precipitation and temperature in the central Great Plains, Int. J. Remote Sens., 22, 3827-3844, https://doi.org/10.1080/01431160010007033, 2001. 
Wagner, W., Lemoine, G., and Rott, H.: A method for estimating soil moisture from ers scatterometer and soil data, Remote Sens. Environ., 70, 191-207, https://doi.org/10.1016/S00344257(99)00036-X, 1999.

Wells, N., Goddard, S., and Hayes, M. J.: A selfcalibrating palmer drought severity index, J. Climate, 17, 2335-2351, https://doi.org/10.1175/15200442(2004)017<2335:aspdsi>2.0.co;2, 2004.
Zhang, F., Zhang, L., Wang, X., and Hung, J.: Detecting agrodroughts in southwest of china using MODIS satellite data, J. Integr. Agr., 12, 159-168, https://doi.org/10.1016/S20953119(13)60216-6, 2013. 